\title{
Health Promotion Capacity Among Chinese Healthcare Professionals and Its Influence on Preventive Health Service Practices
}

\author{
Chi Zhou',*, Fang Tan',*, Sihong Lai', Jingchun Chen', Qi Cai', Xiaoyu Yin', Shuli Guo', Shuang Wu², \\ Lei Yang' \\ 'School of Public Health, Hangzhou Normal University, Hangzhou, 31 I I2I, People's Republic of China; ${ }^{2}$ The Second Affiliated Hospital of Zunyi \\ Medical University, Zunyi, 563100, People's Republic of China \\ *These authors contributed equally to this work \\ Correspondence: Lei Yang, School of Public Health, Hangzhou Normal University, No. 23I8, Yuhangtang Road, Cangqian, Yuhang District, Hangzhou, \\ 3III2I, People's Republic of China, Tel/Fax +86-057I-288655 I0, Email yanglei62@hznu.edu.cn
}

Background: This study evaluated the current health promotion capacity level of Chinese healthcare professionals and explored the association between health promotion capacity and preventive health service practices.

Methods: A total of 124 doctors and 72 nurses were recruited from 6 county hospitals and 12 community health centers from June to August 2019 in Zhejiang Province, China. Health promotion capacity was measured using the revised Chinese version of the Health Promotion Professionals Core Competency Scale.

Results: The mean total score on the health promotion capacity scale was $45.04(\mathrm{SD}=7.30)$. Total health promotion capacity score was negatively associated with county hospitals $(\beta=-0.32, \mathrm{p}<0.001$; Ref: community health center) and positively associated with a monthly income of more than $5001 \mathrm{RMB}(\$ 786.39)(\beta=0.25, \mathrm{p}=0.004$; Ref: less than $5000 \mathrm{RMB}(\$ 786.24))$. All domain scores of the health promotion capacity scale were positively related to preventive health service practices.

Conclusion: Health promotion capacity is one of the most important capacities among healthcare professionals, and there is a particular need to improve nurses' capacity. A higher level of health promotion capacity is beneficial for implementing preventive health services.

Keywords: healthcare professionals, health promotion, primary care, capacity

\section{Introduction}

China is facing the challenge of emerging epidemics of chronic disease; approximately $27.5 \%$ and $11.9 \%$ of residents had hypertension and diabetes, respectively, in 2020. ${ }^{1}$ Effective health promotion is one of the key measures to prevent outbreaks and manage chronic diseases, ${ }^{2}$ such as carrying out health counseling to encourage healthy lifestyles and prevent complications among patients, early identification of residents' chronic disease and ensuring they are at low risk of disease, and supporting residents to participate in health promotion activities. ${ }^{3-5}$ Mental health is a challenge among the global general population; ${ }^{6}$ mental health activities emphasizing the prevention and treatment of mental disordersalongside mental health promotion - may improve public mental health. ${ }^{7}$ Health promotion is an important task in the daily practice of healthcare professionals, ${ }^{8}$ and they should have the knowledge, skills, and attitudes to enable effective health promotion. ${ }^{9,10}$

Due to differences among cultures and healthcare systems, the requirements for health promotion capacity might differ from country to country. For example, Canada encourages healthcare professionals to explore strategies for mobilizing community resources and enhancing community participation. ${ }^{11}$ South Africa emphasizes the capacity to transfer knowledge, work together to solve health problems for residents, and develop health-related capital. ${ }^{12}$ 
There are few health promotion capacity tools or scales that are commonly used worldwide. One is the Canada Promotion Capacity Checklist developed by the Prairie Region Health Promotion Research Centre of Saskatchewan University in 2004, which includes four domains: knowledge, skills, commitment, and resources. ${ }^{13}$ Another is the Australian Health Promotion Capacity Scale, which includes five domains: beliefs about behavior change, intention to promote health, health promotion skills, effectiveness of health promotion, and health-promoting norms. ${ }^{14}$ However, few studies have explored the measurement of health promotion capacity among Chinese healthcare professionals. ${ }^{15,16}$ Since 2016, the Chinese government has promoted a series of health-oriented strategies, including the implementation of the Healthy China 2030 Plan by the State Council of China, ${ }^{17}$ aimed at the promotion of healthier lifestyles, increasing health literacy, and improving mental health status, among others. ${ }^{18}$ The Law on Basic Health Care and Health Promotion was also implemented as the country's first basic and comprehensive healthcare law. ${ }^{19}$ Primary doctors and nurses will be encouraged to participate in more health promotion tasks in their daily work. ${ }^{17}$ It is meaningful to evaluate the current status of health promotion among healthcare professionals in the new era in China, and to provide suggestions to improve their ability.

Health promotion capacity might be affected by gender, age, education, specific job, training frequency, and familiarity with policy; ${ }^{20,21}$ these factors will differ contingent on local cultural differences. For example, gender, years of work experience, and heavy workload were found to be associated with health promotion capacity in Pennsylvania. ${ }^{22}$ Another study showed that length of employment was negatively associated with health promotion knowledge and capacity in South Korea. ${ }^{23}$ In Hong Kong, men aged over 50 years who had practiced medicine for more than 30 years, and who had received training, were significantly associated with more confidence in health promotion. ${ }^{24}$

Previous Chinese studies on healthcare professionals focused on job satisfaction, job burnout and clinical services practices, ${ }^{25,26}$ and few have explored preventive practices. ${ }^{27}$ Healthcare professionals' health promotion capacity has been shown to influence the output of preventive healthcare practices. ${ }^{28-30}$ For example, a study in Ireland found a significant association between doctors' level of health promotion knowledge and physical activity counseling. ${ }^{31}$ Another study in the UK showed that nurses with lower-level skills in health promotion practice were more likely to raise lifestyle issues with patients. ${ }^{32,33}$ However, there is a lack of quantitative studies that assessed the association between health promotion capacity and preventive health service practices. It is important to explore this relationship to improve the quality of preventive health services.

The current study: 1) evaluated the current health promotion capacity of Chinese healthcare professionals, 2) explored the factors that influence health promotion capacity, and 3) investigated the relationships between health promotion capacity and preventive health service practices.

We hypothesized that 1) Chinese healthcare professionals' domain scores on the health promotion capacity scale will be balanced; and 2) their total scores on the health promotion capacity scale will be positively associated with their preventive health service practices.

\section{Materials and Methods}

\section{Participants and Procedure}

A cross-sectional study was carried out from June to August 2019 in three cities (Hangzhou, Deqing, and Yuhuan), which represent well-, moderately-, and less-developed GDP levels in Zhejiang Province. Each city has two or three medical groups, which had been established for approximately one year at the time of the study. Each medical group included one county hospital and several community health service centers. Two medical groups were selected from each city, and one county hospital and two associated community health centers from central and non-central urban areas were selected from each medical group. Thus, a total of six county hospitals and 12 community health centers were selected as investigation sites. We selected two doctors from the internal medicine department of each site, as well as one or two from the surgical medicine department, one from obstetrics or gynecology, and two or three from general medicine. One nurse was selected from the internal medicine department, one or two from obstetrics or gynecology, and one or two from the general medicine department. Participants were required to meet the following inclusion criteria: 1) worked in a local hospital/community health center for at least one year and 2) willing to participate in the study. Data were collected using 
a self-administered questionnaire after obtaining written consent from doctors and nurses. A total of 203 questionnaires were distributed, and 196 valid questionnaires were returned, resulting in a 96.55\% response rate. Ultimately, 124 doctors and 72 nurses completed self-administered questionnaires in this survey. This study was approved by the ethics board of Hangzhou Normal University (No. 2019065).

\section{Measurements}

Health promotion capacity was assessed using the revised Chinese version of the Health Promotion Professionals Core Competency Scale developed in 2015. ${ }^{16}$ This scale includes 11 items that assess two domains: 1) knowledge and skills (7 items) and 2) personal qualities (4 items). Knowledge and skills items measure ability regarding health promotion knowledge, disease risk assessment, and health intervention. Example items are "I master the theories and knowledge of health promotion and disease prevention," "I have enough knowledge of nutrition and healthy diet," "I can assess residents' health promotion demands based on their health status", "I can make plans for disease risk assessment and health intervention," and "I can evaluate the effectiveness of health interventions." Items that assess personal qualities measure health promotion attitude, communication skills, and teamwork awareness in daily work. Example items are "I think health promotion work is very meaningful" and "I am familiar with using communication skills to provide health promotion services". Participants were required to rate each item on a 5-point Likert scale ranging from 1 (strongly disagree) to 5 (strongly agree). Total scores ranged from 11 to 55, such that a higher score indicated a higher level of self-reported health promotion capacity. The Cronbach's alpha coefficients for the original and revised versions of the health promotion capacity scale were 0.96 and 0.97 respectively. ${ }^{34}$ The concurrent validity of the health promotion capacity scale was $\mathrm{R}=0.76(\mathrm{P}<0.001)$, and two domains with eigenvalues over 1 were extracted, explaining $83.96 \%$ of the variance.

A self-developed questionnaire was produced that consisted of two parts. The first part collected demographic information, including age, gender, education level, years of work experience, whether the respondent was working in a hospital or a community health center, technical title, occupation, and monthly income. The second part of the questionnaire assessed practice of preventive health services. The local medical groups have been established for approximately one year; these emphasize primary health promotion. Questions were asked regarding the current situation compared with that before the local medical groups were established. Items included "Have you provided health education activities (eg, health propaganda and mobilization lectures and so on) more frequently?" "Have you provided healthy lifestyle counselling for residents more frequently?" and "Have you provided health care follow-up services for residents more frequently?" Each question was answered as "yes" or "no."

\section{Statistical Analysis}

Data were analyzed using SPSS 23.0 (SPSS Inc., Chicago, IL, USA). Descriptive analyses were performed for the sociodemographic variables. Categorical data are presented as frequencies and percentages, while continuous data are shown as means and standard deviations (SDs). The rank sum test was used to compare the health promotion capacity scores of doctors and nurses. Linear regression was used to analyze the association between demographic characteristics and each health promotion capacity domain score. Logistic regression was used to investigate the association between preventive health service practices and two-dimensional scores on the health promotion capacity scale. Multicollinearity was assessed by Pearson correlation coefficient and by checking the variance inflation factor in a multiple regression model with the same dependent and independent variables. ${ }^{35}$ The $-2 \log$-likelihood ratio test was used to test the overall significance of the model. The fit of the model was assessed using the Hosmer-Lemeshow goodness-of-fit chi-square test. The significance level was set at a two-tailed probability level of $p<0.05$. Missing data were excluded from the analysis.

\section{Results}

\section{Sample Characteristics}

The demographic characteristics of the participants are presented in Table 1. The mean age of the subjects was $35.64 \pm$ 7.60 years, $58.16 \%$ were female, and $76.53 \%$ had at least an undergraduate education. Of the participants, $58.67 \%$ were 
Table I Demographic Characteristics of the Participants (n,\%)

\begin{tabular}{|c|c|c|}
\hline Variate & $\mathbf{n} / \bar{x}$ & $\% /$ SD \\
\hline \multicolumn{3}{|l|}{ Gender } \\
\hline Male & 82 & 41.84 \\
\hline Female & 114 & 58.16 \\
\hline Age & 35.64 & 7.60 \\
\hline$\leq 35$ year & 104 & 53.06 \\
\hline $36-45$ year & 70 & 35.71 \\
\hline$\geq 46$ year & 22 & 11.22 \\
\hline \multicolumn{3}{|l|}{ Education level } \\
\hline Junior college and below & 46 & 23.47 \\
\hline Undergraduate and above & 150 & 76.53 \\
\hline Work years & 13.46 & 8.35 \\
\hline $1-10$ years & 81 & 41.33 \\
\hline$\geq I I$ years & 115 & 58.67 \\
\hline \multicolumn{3}{|l|}{ Hospital category } \\
\hline County hospital & 81 & 41.33 \\
\hline Community health center & 115 & 58.67 \\
\hline \multicolumn{3}{|l|}{ Technical title } \\
\hline Senior & 30 & $|5.3|$ \\
\hline Median & 73 & 37.24 \\
\hline Primary & 93 & 47.45 \\
\hline \multicolumn{3}{|l|}{ Occupation } \\
\hline Doctors & 124 & 63.27 \\
\hline Nurses & 72 & 36.73 \\
\hline \multicolumn{3}{|l|}{ Monthly income } \\
\hline$\leq 5000$ RMB $(\$ 786.24)$ & 108 & 55.10 \\
\hline$\geq 500$ I RMB $(\$ 786.39)$ & 88 & 44.90 \\
\hline
\end{tabular}

employed in community health centers, $47.45 \%$ held primary technical jobs, and their monthly income was below 5000 RMB (\$786.24) (55.10\%). Of the participants, 63.27\% were doctors, and $36.73 \%$ were nurses.

\section{Scores on the Self-Reported Health Promotion Capacity Scale}

Table 2 shows that the mean total score on the health promotion capacity scale was $45.04(\mathrm{SD}=7.30)$. The mean score of the knowledge and skills domain was $28.13(\mathrm{SD}=4.95)$ and that of personal qualities was $16.91(\mathrm{SD}=2.79)$. Compared with nurses, doctors had higher knowledge and skills domain scores $(Z=-2.84, p=0.005)$ and total scale scores $(Z=-2.25$, $\mathrm{p}=0.02)$.

\section{Linear Regression of Demographic Characteristics on Health Promotion Capacity Domain Scores}

The associations between the demographic characteristics and health promotion capacity are presented in Table 3 . The total scores of health promotion capacity were negatively associated with county hospitals $(\beta=-0.32, \mathrm{p}<0.001 ;$ Ref: community health center), and positively associated with a monthly income level of more than 5001 RMB (\$786.39) 
Table 2 The Total and Domain Scores of Health Promotion Capacity Scale

\begin{tabular}{|c|c|c|c|c|c|c|c|c|c|}
\hline \multirow[t]{3}{*}{ Dimension } & \multirow[t]{3}{*}{ Item } & \multirow[t]{3}{*}{ Range } & \multicolumn{2}{|c|}{$\begin{array}{l}\text { All Healthcare } \\
\text { Professionals }(\mathrm{N}=196)\end{array}$} & \multicolumn{2}{|c|}{ Nurses $(\mathbf{N}=72)$} & \multicolumn{2}{|c|}{ Doctors $(N=124)$} & \multirow[t]{3}{*}{$\mathbf{Z}$} \\
\hline & & & $\begin{array}{l}\text { Average } \\
\text { Score }\end{array}$ & $\begin{array}{l}\text { Average } \\
\text { Score of } \\
\text { Each } \\
\text { Item }\end{array}$ & $\begin{array}{l}\text { Average } \\
\text { Score }\end{array}$ & $\begin{array}{l}\text { Average } \\
\text { Score of } \\
\text { Each } \\
\text { Item }\end{array}$ & $\begin{array}{l}\text { Average } \\
\text { Score }\end{array}$ & $\begin{array}{l}\text { Average } \\
\text { Score of } \\
\text { Each } \\
\text { Item }\end{array}$ & \\
\hline & & & $\begin{array}{l}\text { Mean } \\
(\mathrm{SD})\end{array}$ & $\begin{array}{l}\text { Mean } \\
(\mathrm{SD})\end{array}$ & $\begin{array}{l}\text { Mean } \\
(\mathrm{SD})\end{array}$ & $\begin{array}{l}\text { Mean } \\
(\mathrm{SD})\end{array}$ & $\begin{array}{l}\text { Mean } \\
(\mathrm{SD})\end{array}$ & $\begin{array}{l}\text { Mean } \\
\text { (SD) }\end{array}$ & \\
\hline $\begin{array}{l}\text { A.Knowledge and } \\
\text { skills }\end{array}$ & 7 & $7 \sim 35$ & $28.13(4.95)$ & $4.02(0.7 I)$ & $26.82(5.45)$ & $3.83(0.78)$ & $28.89(4.49)$ & $4.13(0.64)$ & $-2.84, p=0.005$ \\
\hline B.Personal qualities & 4 & $4 \sim 20$ & $16.91(2.79)$ & $4.23(0.70)$ & $16.60(3.16)$ & $4.15(0.79)$ & $17.09(2.55)$ & $4.27(0.64)$ & $-1.07, p=0.29$ \\
\hline Total scores & 11 & II 55 & $45.04(7.30)$ & $4.09(0.66)$ & $43.42(8.04)$ & $3.95(0.73)$ & $45.98(6.69)$ & $4.18(0.61)$ & $-2.25, p=0.02$ \\
\hline
\end{tabular}

$(\beta=0.25, \mathrm{p}=0.004$; Ref: less than $5000 \mathrm{RMB}(\$ 786.24))$. Regarding domain scores, knowledge and skills scores were negatively associated with county hospitals $(\beta=-0.28, \mathrm{p}=0.001$; Ref: community health center), and positively associated with a monthly income level of more than 5001 RMB (\$786.39) $(\beta=0.26, p=0.002$; Ref: less than 5000 RMB (\$786.24)). Personal quality scores were negatively associated with county hospitals $(\beta=-0.34, \mathrm{p}<0.001$; Ref: community health center), and positively associated with a monthly income level of more than 5001 RMB (\$786.39) $(\beta=0.19, \mathrm{p}=0.03$; Ref: less than $5000 \mathrm{RMB}(\$ 786.24))$.

\section{Binary Logistic Regression of Health Promotion Capacity Scale Scores on Preventive Health Service Practices}

The associations between health promotion capacity and preventive health services are shown in Table 4. After adjusting for gender, education level, work years, hospital category, technical title, occupation, monthly income, practice of health education activities was positively associated with knowledge and skills (OR $=1.95,95 \%$ CI: 1.34-2.84) and personal qualities $(\mathrm{OR}=2.10,95 \% \mathrm{CI}: 1.48-2.99)$. Healthy lifestyle counseling practice behavior was positively associated with knowledge and skills $(\mathrm{OR}=2.71,95 \% \mathrm{CI}: 1.68-4.37)$ and personal qualities $(\mathrm{OR}=2.07,95 \% \mathrm{CI}: 1.39-3.10)$. Follow-up service practice behavior was positively associated with knowledge and skills $(\mathrm{OR}=2.01,95 \% \mathrm{CI}$ : $1.33-3.05)$ and personal qualities $(\mathrm{OR}=1.71,95 \% \mathrm{CI}: 1.18-2.48)$.

\section{Discussion}

This is the first study to assess health promotion capacity among healthcare professionals after a medical group was established in China. We found that healthcare professionals had a favorable self-reported health promotion capacity (45.04/55). The overall score of the personal quality domain was higher than that of the knowledge and skill domain among healthcare professionals. This result is quite different from those of other studies in Western countries, which reported balanced knowledge and skill levels. ${ }^{36}$ This might be because, first, the health promotion capacity of healthcare professionals in China has received attention in recent years, with related training being instituted that primarily focuses on basic theory and cognition, but lacks skills teaching. Second, there are evidence-based guidelines for primary preventive services in some Western countries, which provide detailed guidance on the content of related services. In China, the government encourages healthcare professionals to carry out these services in their daily work, but without evidence-based guidelines. One study showed that $70.02 \%$ of Chinese doctors and nurses engaged in health promotion activities for less than 10 minutes for each patient, and exhibited a lack of effective health promotion theory and tools. ${ }^{37}$

It is worth noting that doctors overall had higher health promotion knowledge and skills domain scores than nurses. This finding is contrary to previous studies in other countries. ${ }^{38-40}$ This might be for two reasons. First, the number of nurses in China is markedly insufficient; they experience a large amount of pressure from daily clinical nursing work and 
Table 3 Liner Regression of Demographic Characteristics on Each Domain Scores of Health Promotion Capacity Scale (Standardized $\beta$ Value)

\begin{tabular}{|c|c|c|c|c|c|c|c|}
\hline \multirow[t]{2}{*}{ Category } & \multirow[t]{2}{*}{ Variable } & \multicolumn{2}{|c|}{ Knowledge and Skills } & \multicolumn{2}{|c|}{ Personal Qualities } & \multicolumn{2}{|l|}{ Total Scores } \\
\hline & & Standardized $\beta$ & $p$ & Standardized $\beta$ & $p$ & Standardized $\beta$ & $p$ \\
\hline \multirow[t]{2}{*}{ Gender } & Male & 0.10 & 0.21 & 0.08 & 0.36 & 0.10 & 0.23 \\
\hline & Female & Ref & Ref & Ref & Ref & Ref & Ref \\
\hline \multirow[t]{2}{*}{ Education level } & Undergraduate and above & 0.12 & 0.13 & 0.12 & 0.14 & 0.12 & 0.11 \\
\hline & Junior college and below & Ref & Ref & Ref & Ref & Ref & Ref \\
\hline Work years & - & -0.03 & 0.79 & -0.04 & 0.67 & -0.03 & 0.73 \\
\hline \multirow[t]{2}{*}{ Hospital category } & County hospital & -0.28 & 0.001 & -0.34 & $<0.001$ & -0.32 & $<0.001$ \\
\hline & Community health center & Ref & Ref & Ref & Ref & Ref & Ref \\
\hline \multirow[t]{3}{*}{ Technical title } & Senior & -0.09 & 0.41 & 0.02 & 0.86 & -0.05 & 0.62 \\
\hline & Median & -0.09 & 0.31 & -0.02 & 0.79 & -0.07 & 0.43 \\
\hline & Primary & Ref & Ref & Ref & Ref & Ref & Ref \\
\hline \multirow[t]{2}{*}{ Occupation } & Doctors & 0.08 & 0.34 & -0.02 & 0.80 & 0.05 & 0.58 \\
\hline & Nurses & Ref & Ref & Ref & Ref & Ref & Ref \\
\hline \multirow[t]{2}{*}{ Monthly income } & $\geq 500$ I RMB $(\$ 786.39)$ & 0.26 & 0.002 & 0.19 & 0.03 & 0.25 & 0.004 \\
\hline & $\leq 5000$ RMB $(\$ 786.24)$ & Ref & Ref & Ref & Ref & Ref & Ref \\
\hline
\end{tabular}

Table 4 Binary Logistic Regression of Health Promotion Capacity Scale Scores on Preventive Health Services Practice [OR(95\% CI)]

\begin{tabular}{|c|c|c|c|c|c|c|c|}
\hline \multirow[t]{2}{*}{ Category } & \multirow[t]{2}{*}{ Variable } & \multicolumn{2}{|c|}{$\begin{array}{l}\text { Health Education } \\
\text { Activities }\end{array}$} & \multicolumn{2}{|c|}{$\begin{array}{l}\text { Healthy Lifestyle } \\
\text { Counselling }\end{array}$} & \multicolumn{2}{|c|}{$\begin{array}{l}\text { Follow-Up } \\
\text { Services }\end{array}$} \\
\hline & & OR & $95 \% \mathrm{Cl}$ & OR & $95 \% \mathrm{Cl}$ & OR & $95 \% \mathrm{Cl}$ \\
\hline Facl knowledge and skills & - & $1.95 * * *$ & $(1.34,2.84)$ & $2.7 I^{* * * *}$ & $(1.68,4.37)$ & $2.01 * *$ & $(1.33,3.05)$ \\
\hline Fac2 personal qualities & - & $2.10 * * *$ & $(1.48,2.99)$ & $2.07^{* * * *}$ & $(1.39,3.10)$ & $1.71 * *$ & $(1.18,2.48)$ \\
\hline Gender & $\begin{array}{l}\text { Male } \\
\text { Female }\end{array}$ & $\begin{array}{l}0.88 \\
\text { Ref }\end{array}$ & $\begin{array}{l}(0.39,1.97) \\
\operatorname{Ref}\end{array}$ & $\begin{array}{l}0.76 \\
\text { Ref }\end{array}$ & $\begin{array}{l}(0.30,1.92) \\
\operatorname{Ref}\end{array}$ & $\begin{array}{l}1.15 \\
\text { Ref }\end{array}$ & $\begin{array}{l}(0.49,2.74) \\
\text { Ref }\end{array}$ \\
\hline Education level & $\begin{array}{l}\text { Undergraduate and above } \\
\text { Junior college and below }\end{array}$ & $\begin{array}{l}3.08^{*} \\
\operatorname{Ref}\end{array}$ & $\begin{array}{l}(1.22,7.76) \\
\text { Ref }\end{array}$ & $\begin{array}{l}1.61 \\
\text { Ref }\end{array}$ & $\begin{array}{l}(0.53,4.86) \\
\operatorname{Ref}\end{array}$ & $\begin{array}{l}2.29 \\
\text { Ref }\end{array}$ & $\begin{array}{l}(0.83,6.32) \\
\operatorname{Ref}\end{array}$ \\
\hline Work years & - & 1.01 & $(0.95,1.07)$ & 1.02 & $(0.96,1.09)$ & 1.05 & $(0.99,1.11)$ \\
\hline Hospital category & $\begin{array}{l}\text { County hospital } \\
\text { Community health center }\end{array}$ & $\begin{array}{l}0.51 \\
\text { Ref }\end{array}$ & $\begin{array}{l}(0.22,1.16) \\
\text { Ref }\end{array}$ & $\begin{array}{l}0.23^{* *} \\
\operatorname{Ref}\end{array}$ & $\begin{array}{l}(0.09,0.6 \mathrm{I}) \\
\operatorname{Ref}\end{array}$ & $\begin{array}{l}0.32^{*} \\
\text { Ref }\end{array}$ & $\begin{array}{l}(0.13,0.79) \\
\operatorname{Ref}\end{array}$ \\
\hline Technical title & $\begin{array}{l}\text { Senior } \\
\text { Median } \\
\text { Primary }\end{array}$ & $\begin{array}{l}0.95 \\
0.66 \\
\text { Ref }\end{array}$ & $\begin{array}{l}(0.20,4.5 \mathrm{I}) \\
(0.26,1.67) \\
\text { Ref }\end{array}$ & $\begin{array}{l}0.20 \\
0.32 * \\
\text { Ref }\end{array}$ & $\begin{array}{l}(0.03,1.19) \\
(0.11,0.95) \\
\text { Ref }\end{array}$ & $\begin{array}{l}0.11^{*} \\
0.29 * \\
\operatorname{Ref}\end{array}$ & $\begin{array}{l}(0.02,0.62) \\
(0.10,0.84) \\
\text { Ref }\end{array}$ \\
\hline Occupation & $\begin{array}{l}\text { Doctors } \\
\text { Nurses }\end{array}$ & $\begin{array}{l}1.13 \\
\text { Ref }\end{array}$ & $\begin{array}{l}(0.48,2.65) \\
\operatorname{Ref}\end{array}$ & $\begin{array}{l}1.35 \\
\text { Ref }\end{array}$ & $\begin{array}{l}(0.52,3.5 \mathrm{I}) \\
\operatorname{Ref}\end{array}$ & $\begin{array}{l}0.96 \\
\text { Ref }\end{array}$ & $\begin{array}{l}(0.39,2.35) \\
\text { Ref }\end{array}$ \\
\hline Monthly income & $\begin{array}{l}\geq 500 \text { I RMB }(\$ 786.39) \\
\leq 5000 \text { RMB }(\$ 786.24)\end{array}$ & $\begin{array}{l}0.83 \\
\text { Ref }\end{array}$ & $\begin{array}{l}(0.35,1.98) \\
\text { Ref }\end{array}$ & $\begin{array}{l}2.36 \\
\text { Ref }\end{array}$ & $\begin{array}{l}(0.85,6.55) \\
\text { Ref }\end{array}$ & $\begin{array}{l}3.33^{*} \\
\text { Ref }\end{array}$ & $\begin{array}{l}(1.21,9.12) \\
\text { Ref }\end{array}$ \\
\hline
\end{tabular}

Notes: $* P<0.05, * * P<0.01, * * * P<0.001$ 
lack the time and capacity to carry out health promotion activities. ${ }^{23}$ As a result, general practitioners must provide health education services and related skills while treating patients. ${ }^{41}$ Second, residents are more likely to trust doctors than nurses in China. Doctors have greater technical knowledge, education level, and social status than nurses. Doctors are more likely to have a good relationship with patients and find it convenient to carry out health promotion activities. However, the role of nurses has expanded in recent years worldwide, with increased health promotion responsibilities for patients with chronic conditions. And nurses work increasingly in the fields of health promotion and chronic disease prevention. ${ }^{39}$ For example, nurses provide health education and patient counseling aimed at behavior change with patients at risk of lifestyle-related illness in the UK and the US. ${ }^{42-44}$ Accordingly, the Chinese government could consider increasing the number of nurses and enhancing health promotion training for nurses. This would encourage nurses to participate in health promotion activities and redefine the roles and responsibilities of nurses and doctors.

The results of the linear regression showed that the hospital employer category was negatively associated with the total score and the two domain scores. This indicates that the healthcare professionals in community health centers had a higher level of health promotion capacity than did those in county hospitals. This result is consistent with studies in the UK ${ }^{45-47}$ This might be because the family physician contract service is carried out in community health centers under the healthcare system in China. The government has provided funding to promote the delivery of health promotion activities in the family physician contract since 2018, such as healthy lifestyle counseling and healthy behavior interventions. Therefore, the related capacity of healthcare professionals has rapidly strengthened in community health centers. Meanwhile, doctors and nurses in county hospitals focus on clinical treatment and have limited time to carry out health promotion activities. ${ }^{48}$

Monthly income was positively associated with the total score and two domain scores, indicating that income incentive is an important factor in enhancing health promotion capability. This is consistent with a study showing that approximately half of family physicians thought that a lack of economic incentives prevented them from providing health promotion and preventive services in the US. ${ }^{22}$ Without income incentives, it is difficult to mobilize enthusiasm for such work. However, there are no special salary incentives for health promotion services for healthcare professionals in China. All national basic public health services are paid by the capitation payment, and the health promotion service is one of these services. We suggest that some of the clinical income profits might be used to encourage the implementation of health promotion services in the future.

The two domain scores of the health promotion capacity scale were positively associated with all preventive health service practices. This is consistent with previous findings. ${ }^{28,29}$ Healthcare professionals who develop more health promotion knowledge and skills will be more confident in providing healthy lifestyle counseling and follow-up services for residents. Therefore, ensuring health promotion capacity as part of daily training and enhancing health-oriented attitudes might be beneficial for encouraging healthcare professionals to engage in health-promoting activities as part of their routine practice. ${ }^{31}$

This study has some limitations. Firstly, it was carried out in three counties and cities in Zhejiang Province; these selected sample areas have limited representativeness. Secondly, the Chinese version of the health promotion capacity scale is not a validated assessment tool, which limits the external validity of the results of this study. Thirdly, confounding factors such as workload and lifestyle might affect preventive health services practice, we did not collect data regarding such aspects.

\section{Conclusions}

The Chinese healthcare systems is developing towards the health oriented, and health promotion capacity as one of the most important capacities of healthcare professionals, being especially beneficial for improving preventive health service practices. Preventive health service practices have important clinical implications for the prevention of cardiovascular and cerebrovascular diseases, as well as mental illness. In the current study, scores for the personal qualities domain were relatively high, while the lower knowledge and skill domain scores suggest that more specialized training is needed to help healthcare professionals improve their level of practice, such as disease risk assessment, health lifestyle intervention, and so on. The role of nurses needs to be redefined and expanded, with increasing responsibility to promote patient 
health. It is important for healthcare professionals to share accurate health promotion information. The government should prioritize health promotion through appropriate income incentives for healthcare professionals.

\section{Data Sharing Statement}

Data can be requested from the corresponding author. All materials used for the purpose of this study are available on the request of the corresponding author.

\section{Ethics Approval and Consent to Participate}

This study was approved by the ethics board of Hangzhou Normal University (No. 2019065). Written informed consent was obtained from each participant.

\section{Acknowledgments}

We thank the help of doctors and nurses from the six counties hospitals and 12 community health centers of Hangzhou, Deqing, Yuhuan cities, and all the research staffs during the surveys.

\section{Author Contributions}

All authors made a significant contribution to the work reported, whether that is in the conception, study design, execution, acquisition of data, analysis and interpretation, or in all these areas; took part in drafting, revising or critically reviewing the article; gave final approval of the version to be published; have agreed on the journal to which the article has been submitted; and agree to be accountable for all aspects of the work.

\section{Funding}

This study was supported by the Zhejiang Province Philosophy and Social Science Planning Project (No:22NDJC135YB) and Zhejiang College Students' Science and Technology Innovation Program (Xin-Miao Talent Plan) (No:2021R426069).

\section{Disclosure}

The authors declare that they have no competing interests.

\section{References}

1. Bureau of disease prevention and control of national health commission of the people's republic of China. Chinese residents' nutrition and chronic disease report; 2020. Available from: http://www.scio.gov.cn/xwfbh/xwbfbh/wqfbh/42311/44583/index.htm. Accessed October 11, 2021.

2. Altamimi S, Alshoshan F, Al Shaman G, Tawfeeq N, Alasmary M, Ahmed AE. Health promotion practices as perceived by primary healthcare professionals at the Ministry of National Guard Health Affairs, Saudi Arabia. Qatar Med J. 2016;2016(1):1-9. doi:10.5339/qmj.2016.4

3. Canadian Medical Association. The role of physicians in prevention and health promotion. CMAJ. 1995;153(2):208A-D.

4. Kemppainen V, Tossavainen K, Turunen H. Nurses' roles in health promotion practice: an integrative review. Health Promot Int. 2013;28(4):490501. doi:10.1093/heapro/das034

5. Keleher H, Parker R, Abdulwadud O, Francis K. Systematic review of the effectiveness of primary care nursing. Int J Nurs Pract. 2009;15(1):1624. doi:10.1111/j.1440-172X.2008.01726.x

6. García-Gutiérrez MS, Navarrete F, Gasparyan A, Austrich-Olivares A, Sala F, Manzanares J. Cannabidiol: a potential new alternative for the treatment of anxiety, depression, and psychotic disorders. Biomolecules. 2020;10(11):1-34. doi:10.3390/biom10111575

7. Collins PY. What is global mental health? World Psychiatr. 2020;19(3):265-266. doi:10.1002/wps.20728

8. Brotonsc C, Björkelund C, Bulc M, et al. Prevention and health promotion in clinical practice: the views of general practitioners in Europe. Prev Med. 2005;40(5):595-601. doi:10.1016/j.ypmed.2004.07.020

9. Smith BJ, Tang KC, Nutbeam D. WHO health promotion glossary: new terms. Health Promot Int. 2006;21(4):340-345. doi:10.1093/heapro/da1033

10. Battel-Kirk B, Barry MM, Taub A, Lysoby L. A review of the international literature on health promotion competencies: identifying frameworks and core competencies. Glob Health Promot. 2009;16(2):12-20. doi:10.1177/1757975909104100

11. Anderson D, Plotnikoff RC, Raine K, Cook K, Smith C, Barrett L. Towards the development of scales to measure "will" to promote heart health within health organizations in Canada. Health Promot Int. 2004;19(4):471-481. doi:10.1093/heapro/dah409

12. Van Den Broucke S, Jooste H, Tlali M, et al. Strengthening the capacity for health promotion in South Africa through international collaboration. Glob Health Promot. 2010;17(2 Suppl):6-16. doi:10.1177/1757975910363923

13. University of Saskatchewan. Health promotion capacity checklists: health Promotion. 2017.

14. Maujean A, Kendall E, Ehrlich C, Kisely S. The capacity for health promotion survey. Gen Hosp Psychiatry. 2014;36(6):594-598. doi:10.1016/j. genhosppsych.2014.08.007 
15. Liu Z, Tian L, Chang Q, Sun B, Zhao Y. A competency model for clinical physicians in China: a cross-sectional survey. PLoS One. 2016;11(12):117. doi:10.1371/journal.pone.0166252

16. Wang Y, Ruan MZ, Wang YH. Construction of core competency evaluation index system for health management professionals. Chin Gen Pract. 2015;18(25):3010-3015. doi:10.3969/j.issn.1007-9572.2015.25.003

17. State Council. "Healthy China in 2030" program outline; 2016. Available from: http://www.nhfpc.gov.cn/guihuaaxxs/s3586s/201610/ 21d120c917284007ad9c7aa8e9634bb4.shtml. Accessed January 23, 2022.

18. Zhu C, Xu X, Zhang W, Chen J, Evans R. How health communication via tik tok makes a difference: a content analysis of tik tok accounts run by Chinese provincial health committees. Int J Environ Res Public Health. 2020;17(1). doi:10.3390/ijerph17010192

19. Liu Y, Zhang M, Li R, et al. Risk assessment of workplace violence towards health workers in a Chinese hospital: a cross-sectional study. BMJ Open. 2020;10(12):e042800. doi:10.1136/bmjopen-2020-042800

20. Johansson HS, Weinehall L, Weinehall L, Weinehall L. Reorientation to more health promotion in health services - a study of barriers and possibilities from the perspective of health professionals. J Multidiscip Healthc. 2010;213. doi:10.2147/jmdh.s14900

21. Shi L, Liu J, Xu L. Factors associated with health education delivery by rural doctors for tuberculosis patients in Shandong Province, China. Health Policy (New York). 2010;95(1):57-61. doi:10.1016/j.healthpol.2009.10.004

22. Luquis RR, Paz HL. Attitudes about and practices of health promotion and prevention among primary care providers. Health Promot Pract. 2015;16(5):745-755. doi:10.1177/1524839914561516

23. Kim HS, Lee CY, Lee TW, Ham OK. Effects of a national health promotion project on knowledge, perception, and competency of health care workers in Korea. J Community Health Nurs. 2004;21(1):29-38. doi:10.1207/s15327655jchn2101_3

24. Abdullah ASM, Rahman AS, Suen CW, et al. Investigation of Hong Kong doctor's current knowledge, beliefs, attitudes, confidence and practices: implications for the treatment of tobacco dependency. J Chin Med Assoc. 2006;69(10):461-471. doi:10.1016/S1726-4901(09)70310-7

25. Chen L, Liu J, Yang H, et al. Work-family conflict and job burn-out among Chinese doctors: the mediating role of coping styles. Gen Psychiatr. 2018;31:4. doi:10.1136/gpsych

26. Jin Y, Wang H, Wang D, Yuan B. Job satisfaction of the primary healthcare providers with expanded roles in the context of health service integration in rural China: a cross-sectional mixed methods study. Hum Resour Health. 2019;17(1). doi:10.1186/s12960-019-0403-3

27. Lin MJ, Wang J, Gao HY, Yin HM, Hu QL. Inventory survey of clinical preventive services in township hospital of JI'AN. J Jinggangshan Univ. 2016;37(1):102-106

28. Rubio-Valera M, Pons-Vigués M, Martínez-Andrés M, Moreno-Peral P, Berenguera A, Fernández A. Barriers and facilitators for the implementation of primary prevention and health promotion activities in primary care: a synthesis through meta-ethnography. PLoS One. $2014 ; 9(2)$ :e89554. doi:10.1371/journal.pone.0089554

29. Geense WW, van de Glind IM, Visscher TLS, van Achterberg T. Barriers, facilitators and attitudes influencing health promotion activities in general practice: an explorative pilot study. BMC Fam Pract. 2013;14(1):1. doi:10.1186/1471-2296-14-20

30. Cohidon C, Wild P, Senn N. A structural equation model of the family physicians attitude towards their role in prevention: a cross-sectional study in Switzerland. Fam Pract. 2018;36(3):297-303. doi:10.1093/fampra/cmy063

31. O’Brien S, Prihodova L, Heffron M, Wright P. Physical activity counselling in Ireland: a survey of doctors' knowledge, attitudes and self-reported practice. BMJ Open Sport Exer Med. 2019;5(1):1-10. doi:10.1136/bmjsem-2019-000572

32. Ienatsch G. Knowledge, attitudes, treatment practices, and health behaviors of nurses regarding blood cholesterol. J Contin Educ Nurs. 1999;30 (1):13-19. doi:10.3928/0022-0124-19990101-04

33. Kelly M, Wills J, Sykes S. Do nurses' personal health behaviours impact on their health promotion practice? A systematic review. Int J Nurs Stud. 2017;76:62-77. doi:10.1016/j.ijnurstu.2017.08.008

34. Wang Y, Ruan MZ. An empirical study on the core competence evaluation index system for health management professionals. Chongqing Med. 2016;45(17):2427-2429. doi:10.3969/j.issn.1671-8348.2016.17.045

35. Allison PD. Logistic Regression Using the SAS System: Theory and Application. Wiley-interscience. 2008.

36. McFarlane K, Devine S, Judd J, Nichols N, Watt K. Workforce insights on how health promotion is practised in an aboriginal community controlled health service. Aust J Prim Health. 2017;23(3):243-248. doi:10.1071/PY16033

37. Wang XH, Zhang M, Pu YJ, et al. Study on current situation and countermeasures of hospital - based health education in Lanzhou City. Chin $J$ Health Educ. 2020;36(4). doi:10.16168/j.cnki.issn.1002-9982.2020.04.014

38. McCarthy G, Cornally N, Moran J, Courtney M. Practice nurses and general practitioners: perspectives on the role and future development of practice nursing in Ireland. J Clin Nurs. 2012;21(15-16):2286-2295. doi:10.1111/j.1365-2702.2012.04148.x

39. Maier CB, Budde H, Buchan J. Nurses in expanded roles to strengthen community-based health promotion and chronic care: policy implications from an international perspective; A commentary. Isr J Health Policy Res. 2018;7(1). doi:10.1186/s13584-018-0257-5

40. Murashima S, Hatono Y, Whyte N, Asahara K, Hlth DS. Public health nursing in Japan: new opportunities for health promotion. Public Health Nurs. 1999;16:133-139.

41. Zhou H, Zhang W, Zhang S, et al. Health providers' perspectives on delivering public health services under the contract service policy in rural China: evidence from Xinjian County. BMC Health Serv Res. 2015;15(1). doi:10.1186/s12913-015-0739-x

42. Jose Duaso MM, Cheung MA, Director PB. Issues and innovations in nursing practice. Health promotion and lifestyle advice in a general practice: what do patients think? Available from: www.who.int. Accessed February 10, 2022.

43. Barnes H, Richards MR, McHugh MD, Martsolf G. Rural and nonrural primary care physician practices increasingly rely on nurse practitioners. Health Aff. 2018;37(6):908-914. doi:10.1377/hlthaff.2017.1158

44. Bodenheimer T, Bauer L. Rethinking the primary care workforce — an expanded role for nurses. $N$ Engl $J$ Med. 2016;375(11):1015-1017. doi:10.1056/NEJMp1606869

45. Wang F, Lu ZX. The model of health service delivery in the UK and the main characteristics of the health care system. Foreign Med Soc Med Fascicles. 2005;22(4):145-149. doi:10.3969/j.issn.1673-5625.2005.04.001

46. Kelley K, Abraham C. Health promotion for people aged over 65 years in hospitals: nurses' perceptions about their role. $J$ Clin Nurs. $2007 ; 16$ (3):569-579. doi:10.1111/j.1365-2702.2006.01577.x

47. Boon A, Yan J, Liu K, You LM. Development and thinking of advanced clinical nursing in UK. Chin Nurs Manag. 2007;7(8):16-19.

48. Chen Z. Launch of the health-care reform plan in China. Lancet. 2009;373(9672):1322-1324. doi:10.1016/S0140-6736(09)60753-4 


\section{Publish your work in this journal}

The Journal of Multidisciplinary Healthcare is an international, peer-reviewed open-access journal that aims to represent and publish research in healthcare areas delivered by practitioners of different disciplines. This includes studies and reviews conducted by multidisciplinary teams as well as research which evaluates the results or conduct of such teams or healthcare processes in general. The journal covers a very wide range of areas and welcomes submissions from practitioners at all levels, from all over the world. The manuscript management system is completely online and includes a very quick and fair peer-review system. Visit http://www.dovepress.com/testimonials.php to read real quotes from published authors.

Submit your manuscript here: https://www.dovepress.com/journal-of-inflammation-research-journal 